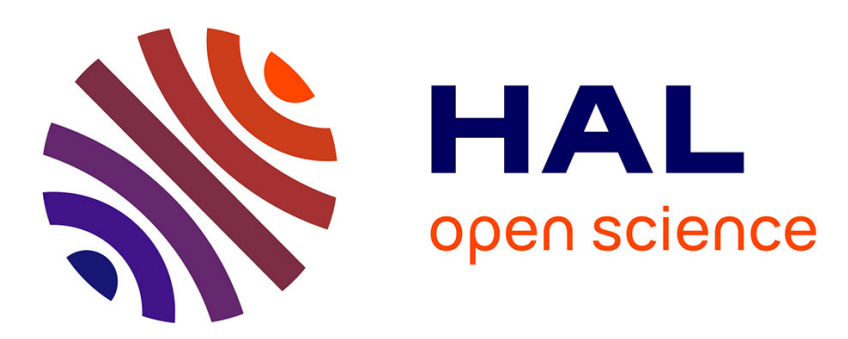

\title{
A four-point bending test for the bonding evaluation of composite pavement
}

Manitou Hun, Armelle Chabot, Ferhat Hammoum

\section{To cite this version:}

Manitou Hun, Armelle Chabot, Ferhat Hammoum. A four-point bending test for the bonding evaluation of composite pavement. 7th Rilem International Conference on Cracking in Pavements, Jun 2012, France. p.51-60, fig., graphiques, ill. en couleurs, bibliogr., 10.1007/978-94-007-4566-7_6 . hal-00845902

\section{HAL Id: hal-00845902 https://hal.science/hal-00845902}

Submitted on 18 Jul 2013

HAL is a multi-disciplinary open access archive for the deposit and dissemination of scientific research documents, whether they are published or not. The documents may come from teaching and research institutions in France or abroad, or from public or private research centers.
L'archive ouverte pluridisciplinaire HAL, est destinée au dépôt et à la diffusion de documents scientifiques de niveau recherche, publiés ou non, émanant des établissements d'enseignement et de recherche français ou étrangers, des laboratoires publics ou privés. 


\title{
A four-point bending test for the bonding evaluation of composite pavement
}

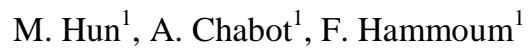 \\ ${ }^{1}$ LUNAM Université, IFSTTAR, Route de Bouaye, CS4, F-44344 \\ Bouguenais Cedex, France
}

\begin{abstract}
The aim of this paper is to present a specific four-point bending test with a specific model to help investigate the crack initiation and propagation at the interface between layers of composite pavements. The influence of the geometry on the delamination phenomenon in specimens is analyzed. Considering the deflection behavior of specimens, both experimental and analytical results are compared. Two different types of interface (concrete / asphalt and asphalt / concrete) are tested in static conditions. Different failure mechanisms whose mainly delamination is observed. The crack mouth opening displacement is monitoring by means of linear variable differential transducer (LVDT). The strain energy release rate is provided and compared successfully to the literature.
\end{abstract}

\section{Introduction}

Due to shrinkage phenomenon occurred in cement materials, the existing vertical crack through the cement concrete layer combined to environmental and traffic loadings affects the durability of composite pavements made with asphalt and cement materials. Two main problems have to be investigated: i) debonding mechanisms at the interface between two layers; ii) reflective cracking phenomenon through asphalt overlay or corner cracks in concrete overlay. This paper deals with the study of debonding. Previous research works have proposed some experimental devices to characterize the bond strength of asphalt-concrete interface in mode I [1]. But the combined normal and shear stresses near the edge of the layer as the vertical crack usually initiates and propagates the delamination [1]. The optimum design incorporating these variables has not been done yet. Mixed mode test to evaluate the delamination resistance is needed. On site, only few devices [4-5] allow testing the bond strength in mixed-mode. The literature review offers interesting ideas especially those on reinforced concrete beams and on concrete beams strengthened with composite materials [6]. 
In this paper, we propose to adapt existing four-point bending test (4PB) to bimaterial specimens made with asphalt and cement material layers as illustrated in Figure 1. By using a specific elastic model, the influence of the specimen geometry and the material characteristics on internal stresses is presented. Then, experimental program is described and a discussion on static results is given.
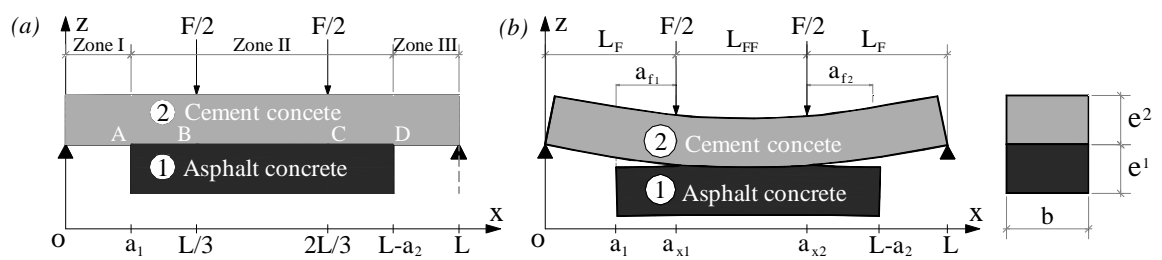

Figure 1. (a) Schematic of test configuration, (b) Schematic adapted for calculating strain energy release rate calculation

\section{Quasi-analytical investigation}

The Multi-particle Model of Multi-layer Materials with 5 equilibrium equations per layer (M4-5n, n: total number of layers) [2] used to calculate stress and strain energy release rate on the 4PB test (Figure 1.b) is briefly presented. Considering homogenous, elastic and isotropic material assumptions, the specimen design is studied in order to optimize stresses to cause delamination between layers.

\section{Introduction to the M4-5n}

The M4-5n has five kinematic fields per layer $\mathrm{i}(i \in\{1, \ldots, n\})$ : the average plane displacement $U_{\alpha}^{i}(x, y)$, the average out of plane $U_{3}^{i}(x, y)$ and the average rotations $\Phi_{\alpha}^{i}(x, y) \quad(\alpha \in\{1,2\})$. Stress field is assumed to be written with polynomial approximation in $\mathrm{z}$ (vertical direction) per layer i (characterized by $e^{i}, E^{i}, v^{i}$, its thickness, Young modulus and Poisson ratio parameters). Its coefficients are expressed with the use of the classical Reissner generalized stress fields in $(x, y)$ per layer i. These polynomial approximations have the advantage to define the normal stresses $v^{i, i+1}(x, y)$ and the shear stresses $\tau_{\alpha}^{i, i+1}(x, y)$ at the interface between $\mathrm{i}$ and $\mathrm{i}+1$ layers. Theses stress fields are responsible for the delamination between layers at the edge or cracking location points. Hellinger-Reissner's formulation reduces the real $3 \mathrm{D}$ problem to the determination of regular plane fields $(\mathrm{x}, \mathrm{y})$ per layer $\mathrm{i}$ and interface $\mathrm{i}, \mathrm{i}+1$ (and $\mathrm{i}-1, \mathrm{i})$. This model can be viewed as superposition of $n$ Reissner's plates, connected by means of an elastic energy that depends on the interlaminar stress fields [2]. The M4-5n advantage is to give finite value of stresses near the edge or crack permitted to identify easily delamination criteria [3]. 
In order to simplify the analysis, the 4PB test presented in Figure 1.a is simulated under the assumption of plane strain. Then, the mechanical fields depend only on the variable $x$. The problem is divided in three zones (see Figure 1.b). By mean of shear forces $Q_{1}^{i}(x)$ of layers 1 and 2, linking conditions of displacements, forces and moments between zones, the first and last single layer zone $\left(x \in\left[0, a_{1}\right]\right.$ and $\left.x \in\left[L-a_{2}, L\right]\right)$ allow to pass on the support conditions of the beam at the bilayer zone $\left(x \in\left[a_{1}, L-a_{2}\right]\right)$. On this central zone (where $n=2$ ), different manipulations of M4-5n equations let to put finally into a system of second order differential equations in function of $x$ only with the form Eqn. (1)

$$
A X^{\prime \prime}(x)+B X(x)=C \quad \text { with } \quad X(x)=\left(\begin{array}{c}
U_{1}^{1}(x) \\
\Phi_{1}^{1}(x) \\
Q_{1}^{1}(x) \\
U_{1}^{2}(x) \\
\Phi_{1}^{2}(x)
\end{array}\right)
$$

where $\mathrm{A}, \mathrm{B}$, and $\mathrm{C}$ are the analytical matrices functions of geometric parameters, elastic characteristics of material behaviors and loading conditions specified (Figure 1.a). The expression of A, B, and C are given in Eqn. (2-4):

$$
\begin{aligned}
& A=\left(\begin{array}{ccccc}
-\frac{e^{1^{2}} E^{1}}{2\left(1-v^{1^{2}}\right)} & \frac{e^{1^{3}} E^{1}}{12\left(1-v^{2^{2}}\right)} & 0 & 0 & 0 \\
\frac{4}{15}\left(\frac{e^{1^{2}}}{\left(1+v^{1}\right)}+\frac{e^{1} e^{2} E^{1}\left(1+v^{2}\right)}{E^{2}\left(1-v^{1^{2}}\right)}\right) & 0 & 0 & 0 & 0 \\
\left(\frac{e^{1}}{\left.5\left(1+v^{1}\right)-\frac{e^{1} E^{1}\left(1+v^{2}\right)}{5 E^{2}\left(1-v^{1^{2}}\right)}\right)}\right. & 0 & -\frac{13}{35}\left(\frac{e^{1}}{E^{1}}+\frac{e^{2}}{E^{2}}\right) & 0 & 0 \\
\left.-\frac{e^{1} e^{2} E^{1}}{2\left(1-v^{1^{2}}\right.}\right) & 0 & 0 & 0 & \left.\frac{e^{2^{3}} E^{2}}{12\left(1-v^{2^{2}}\right.}\right) \\
\frac{e^{1} E^{1}}{1-v^{1^{2}}} & 0 & 0 & \frac{e^{2} E^{2}}{1-v^{2^{2}}} & 0
\end{array}\right) \\
& B=\left(\begin{array}{ccccc}
0 & 0 & -1 & 0 & 0 \\
-1 & -\frac{e^{1}}{2} & \left(\frac{1+v^{1}}{5 E^{1}}-\frac{1+v^{2}}{5 E^{2}}\right) & 1 & -\frac{e^{2}}{2} \\
0 & -1 & \frac{12\left(1+v^{1}\right)}{5 e^{1} E^{1}}+\frac{12\left(1+v^{2}\right)}{5 e^{2} E^{2}} & 0 & 1 \\
0 & 0 & 1 & 0 & 0 \\
0 & 0 & 0 & 0 & 0
\end{array}\right) ; \quad C=\left(\begin{array}{c}
-\frac{1+v^{2}}{5 E^{2}} \frac{F}{2 \times 1000} \\
\frac{12\left(1+v^{2}\right)}{5 e^{2} E^{2}} \frac{F}{2 \times 1000} \\
\frac{F}{2 \times 1000} \\
0
\end{array}\right) \text {, if } x \in\left[a_{1}, \frac{L}{3}[\right. \\
& C=\left(\begin{array}{l}
0 \\
0 \\
0 \\
0 \\
0
\end{array}\right) \text {, if } x \in\left[\frac{L}{3}, \frac{2 L}{3}\left[; C=\left(\begin{array}{c}
\frac{1+v^{2}}{5 E^{2}} \frac{0}{2 \times 1000} \\
-\frac{12\left(1+v^{2}\right)}{5 e^{2} E^{2}} \frac{F}{2 \times 1000} \\
-\frac{F}{2 \times 1000} \\
0
\end{array}\right) \text {, if } x \in\left[\frac{2 L}{3}, L-a_{2}\right]\right.\right.
\end{aligned}
$$


The shear stresses $\tau_{1}^{1,2}(x)$ and normal stresses $v^{1,2}(x)$ of M4-5n at the interface between layer 1 and 2, are obtained analytically in function, respectively, of the unknowns of the system of Eqn. (1) and their derivative by the Eqn. (5) of interface behavior, and the equilibrium equation of shear forces of Eqn. (6). The sum of shear force of layers has to verify the condition as indicating in Eqn. (7).

$$
\begin{aligned}
& \tau_{1}^{1,2}(x)=15 E^{1} E^{2} \frac{\left(U_{1}^{2}(x)-U_{1}^{1}(x)-\frac{e^{1}}{2} \Phi_{1}^{1}(x)-\frac{e^{2}}{2} \Phi_{1}^{2}(x)+\frac{1+v^{1}}{5 E^{1}} Q_{1}^{1}(x)+\frac{1+v^{2}}{5 E^{2}} Q_{1}^{2}(x)\right)}{4\left(e^{1} E^{2}\left(1+v^{1}\right)+e^{2} E^{1}\left(1+v^{2}\right)\right)} \\
& v^{1,2}(x)=-Q_{1}^{1}(x) \\
& Q_{1}^{1}(x)+Q_{1}^{2}(x)=\frac{F}{2 \times 1000} \text { if } x \in\left[a_{1}, \frac{L}{3}\left[; 0 \text { if } x \in \left[\frac{L}{3}, \frac{2 L}{3}\left[;-\frac{F}{2 \times 1000} \text { if } x \in\left[\frac{2 L}{3}, L-a_{2}\right]\right.\right.\right.\right.
\end{aligned}
$$

Eqn. (8) gives the M4-5n elastic energy $\mathrm{W}_{\mathrm{e}}$. According to linear elasticity theory for a system under constant applied load, the energy release rate can be expressed as in Eqn. (9) in case of the crack propagation along the interface (Figure 1.b).

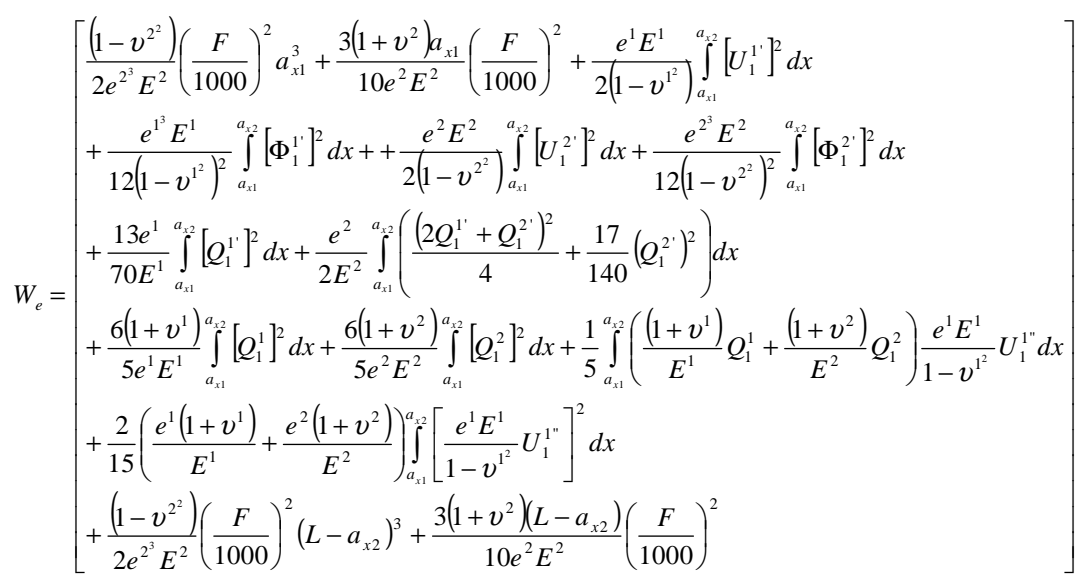

$$
\begin{aligned}
& G=\frac{\partial W_{e}}{\partial A}
\end{aligned}
$$

Both the methods of adimentionalisation and numerical resolution of equations by the Newmark finite difference scheme used by Pouteau [4] and Le Corvec [7] are adapted to this test. This method is programmed under the free software Scilab. For a symmetrical case, the excellent convergence of normal and shear stresses at the interface between layers at $x=a_{1}$ and $x=a_{2}$ is obtained in [8]. It has shown that the discretization of the $\mathrm{x}$ variable into 1200 elementary segments is sufficient. One simulation takes few seconds (CPU time). Interface ruptures are expected in mixed mode (mode I and II). The results have been compared successfully with finite element calculations and different static tests on Alu/PVC structure [8]. 


\section{Effect of the specimen geometry and material characteristics on stress field}

In the following, M4-5n simulations are done on material characteristics presented in Table I. The total load of $4 \mathrm{kN}$ is chosen. The specimen geometry takes into account the space constraints of the test and heterogeneity of used material (span length $420 \mathrm{~mm}$, width $120 \mathrm{~mm}$, each layer thickness $60 \mathrm{~mm}$ ). Half of total load is applied at each third of span length.

The equivalent elastic modulus of the asphalt material depends of the temperature and the loading speed conditions. Simulations are performed for $1<E_{2} / E_{1}<60$ in a symmetric case $a_{1}=a_{2}=70 \mathrm{~mm}$. Figure 2 shows that the more the Young modulus ratio between asphalt material (layer 1) and concrete material (layer 2) decreases, the more the tensile stress intensity at the bottom of layer 2 is maximal at points A and $\mathrm{D}$ relative to point $\mathrm{B}$ and $\mathrm{C}$, and the more the intensities of normal and shear interface stresses are raised in absolute value at these points. This M4-5n parametric analysis indicates that the tensile stress at the bottom of the concrete layer 2 is in competition with interface stresses depending on the modulus of the asphalt. This variation influences the specimen rupture mode during the test.
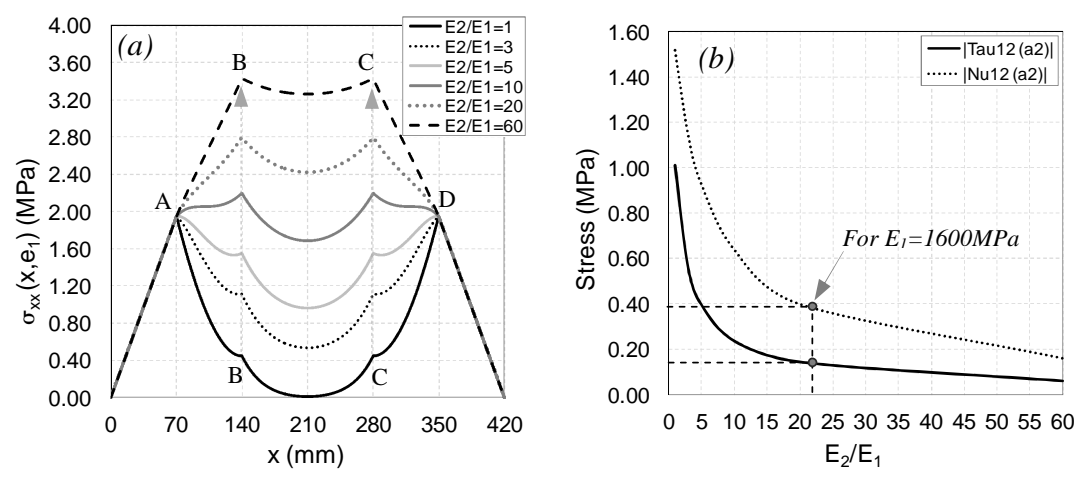

Figure 2. Effect of Young modulus ratio between layers: (a) on the tensile stress at the bottom of layer $2\left(a_{1}=a_{2}=70 \mathrm{~mm}\right)$, (b) on the interface normal $\left(v^{1,2}\right)$ and shear

$\left(\tau^{1,2}\right)$ stresses at $\mathrm{x}=\mathrm{a}_{2}=70 \mathrm{~mm}$

Due to the specimen symmetry of preliminary results presented in [8], delamination can occur first or simultaneously with failure in concrete on either side of the specimen. To reduce the experimental cost for measuring the crack propagation and to get the maximum areas of damage towards one edge only, asymmetric specimens are explored numerically in the following. The length $a_{1}$ is fixed to $40 \mathrm{~mm}$ with respect to the allowable distance from support to the edge of layer 1. For a low asphalt modulus condition, Figure 3 shows M4-5n simulations for a variable $a_{2}$ length. In Figure 3.a, the more the length $a_{2}$ increases, the more the tensile stress intensity at the bottom of concrete layer 2 is increasing under the loading point $\mathrm{C}$ and the more interface normal and shear stresses increase at the 
edge $\left(x=a_{2}\right)$ (Figure 3.b). The parametric analysis confirms that the intensity of interface stresses at the edge $\left(x=a_{2}\right)$ is increasing from $20 \%$ to $60 \%$ compared to those on the other side when the length $\mathrm{a}_{2}$ is increasing. A compromise is still to be found between the tensile stress at the base of cement concrete layer and the shear stresses as well as the normal stresses at the edge of the interface.
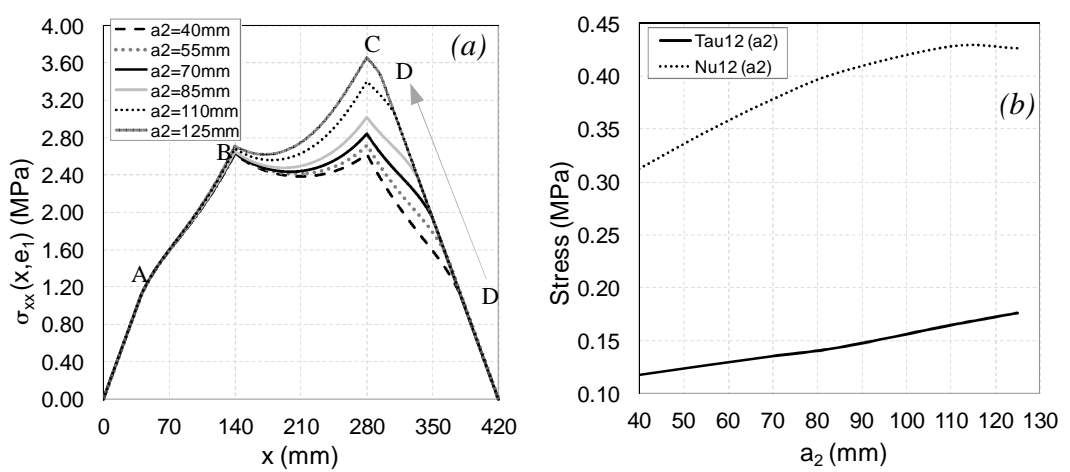

Figure 3. Effect of variation of length $\mathrm{a}_{2}\left(\mathrm{E}_{1}=1600 \mathrm{MPa}\right)$ : (a) on the tensile stress at the base of concrete layer, (b) on the normal $\left(v^{1,2}\right)$ and shear $\left(\tau^{1,2}\right)$ stress at $\mathrm{x}=\mathrm{a}_{2}$

\section{Experimental program}

In this study, two types of interface were tested; (a) type I - concrete over asphalt known as Ultra Thin Whitetopping (UTW), (b) type II - asphalt bonded with concrete by a tack coat layer. The crack monitoring technique is investigated.

\section{Test specimens}

In order to allow evaluation of bonding behavior, only one type of asphalt and cement concrete were used for all samples (see Table I). A semi-coarse bituminous mix with aggregate size $0 / 10$ and bitumen grade $35 / 50$ is used. The cement CEM I $52.5 \mathrm{R}$ and the aggregate size $0 / 11$ are used for cement concrete layer. Two types of specimen were made; (a) type I - concrete over asphalt known as Ultra Thin Whitetopping (UTW), (b) type II - asphalt overlay concrete with an intermediate tack coat layer. For type I, the cement concrete layer was cast directly on the prefabricated asphalt slab. For type II, the surface of concrete layer was cleaned by water blasting before tack coat placement. Then, the tack coat was placed on the concrete layer. A classical emulsion (C69 B 4) used for tack coat was kept at $45^{\circ} \mathrm{C}$ in autoclave. After placing the emulsion with the dosage of $0.4 \mathrm{~kg} / \mathrm{m}^{2}$ of residual binder on concrete layer and leaving for 24 hours, the asphalt layer was placed and compacted by means of the plate compactor developed by LCPC. The composite slabs were sawed into a required dimension (see Table II). 
Table I. Material characteristics

\begin{tabular}{llllll}
\hline Material & $\mathrm{E}(\mathrm{MPa})$ & $v$ & $\%$ air void & $\mathrm{R}_{\mathrm{t}}(\mathrm{MPa})$ & $\mathrm{R}_{\mathrm{c}}(\mathrm{MPa})$ \\
\hline Cement concrete & $34878 \mathrm{MPa}$ & 0.25 & 2.57 & 3.46 & 47.67 \\
Asphalt concrete & $11258\left(15^{\circ} \mathrm{C}, 10 \mathrm{~Hz}\right)$ & 0.35 & 9.59 & - & - \\
\hline
\end{tabular}

Table II. Dimensions of bilayer specimens and static test conditions $(0.7 \mathrm{~mm} / \mathrm{min})$

\begin{tabular}{lllll}
\hline Specimen name & $\mathrm{L} / \mathrm{e} / \mathrm{b} / \mathrm{a}_{1} / \mathrm{a}_{2}(\mathrm{~mm})$ & $\mathrm{L}_{\text {total }}(\mathrm{mm})$ & Temperature $\left({ }^{\circ} \mathrm{C}\right)$ & Test duration $(\mathrm{s})$ \\
\hline Type I-PT-3-1 & $420 / 60 / 120 / 70 / 70$ & 480 & 20.0 & 20.0 \\
Type I-PT-3-2 & $420 / 60 / 120 / 70 / 70$ & 480 & 21.0 & 18.0 \\
Type I-PT-1-3 & $420 / 60 / 100 / 70 / 70$ & 480 & 20.0 & 28.0 \\
Type I-PT-3-3 & $420 / 60 / 100 / 70 / 70$ & 480 & 22.0 & 25.0 \\
Type I-PT-1-1 & $420 / 60 / 120 / 70 / 70$ & 480 & 21.0 & 17.5 \\
Type I-PT-1-2 & $420 / 60 / 100 / 70 / 70$ & 480 & 4.0 & 10.5 \\
Type II-PT-1-1 & $420 / 60 / 120 / 70 / 70$ & 480 & 6.0 & 13.4 \\
Type II-PT-1-3 & $420 / 60 / 100 / 70 / 70$ & 480 & 20.5 & 12.5 \\
Type II-PT-2-1 & $420 / 60 / 120 / 40 / 70$ & 480 & 22.0 & 11.0 \\
Type II-PT-2-3 & $420 / 60 / 100 / 40 / 70$ & 480 & 20.5 & 8.3 \\
\hline
\end{tabular}

\section{Test setup and conditions}

To avoid any problems with the viscoelasticity and the thermo-susceptibility of asphalt material, the loading points and supports are placed on the concrete layer (Figure 1). The specimen geometry is designed to simulate the maximum stress intensity towards the edges of interface. Testing was performed by a hydraulic press. A linear variable differential transducer (LVDT) placed in the middle height of specimen section at the midspan was employed for measuring the deflection and controlling the imposed displacement test. The 4PB tests were conducted for bilayer specimens for various environmental conditions. During the test, the specimen was placed in a climatic chamber. The test temperatures and loading rates for each specimen are shown in Table II.

\section{Crack propagation monitoring}

An ideal way of measuring the crack growth should give the possibility of continuous crack length determination without influencing the specimen or the delamination process itself. LVDT technique was chosen for this study. It consisted on using two LVDT per specimen edge fixed on asphalt layer and its respective ends supported on aluminum sheets attached to concrete layer (Figure 4). The two LVDT were placed at $d_{0}=10$ and $d_{0}+d_{1}=40 \mathrm{~mm}$ distances from the edge. Figure 4.b represents the crack mouth opening displacement (CMOD) measured by the LVDT sensors in function of load and time. The crack length of delamination $l_{\mathrm{f}}$ is determined by knowing $\mathrm{w}_{1}$ and $\mathrm{w}_{2}$ values measured by LVDT during the test. Its expression is given in Eqn. (10) (Figure 4.b).

$$
l_{f}=d_{0}+d_{1}+\frac{w_{2} d_{1}}{w_{1}-w_{2}}
$$




\section{Results and discussion}

\section{Identification of failure phenomenon and influence of interface between layers}

Various kinds of failure mode were exhibited by the bilayer specimens under 4PB test around $20^{\circ} \mathrm{C}$. Typical specimens after failure are depicted in Figure 4.a.
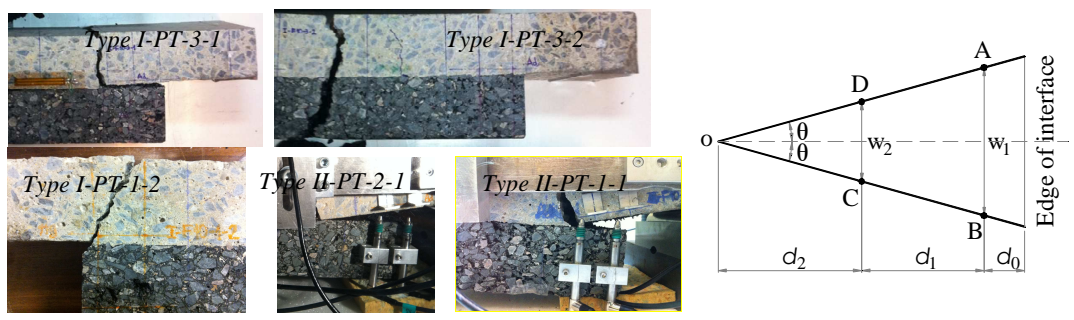

Figure 4. (a) Typical failures of specimens, (b) Schematization of CMOD

Both types I and II specimens were delaminated by this proposed test. At $20^{\circ} \mathrm{C}$, most $(80 \%)$ of type I specimens were delaminated at the interface between layers. Only for one specimen (Type I-PT-3-2), a failure was observed in the central zone between the loading location points. The crack is propagated vertically from the bottom of the asphalt layer to the top of the concrete layer. Figure 2.a shows that a maximum tensile stress exists in this central part when the modulus ratio is high and if any defect in the material exists the crack can occurred. At low temperature $\left(4^{\circ} \mathrm{C}\right)$, one specimen failure was located at the bottom of the concrete layer between central and edge zones (Type I-PT-1-2) which confirms the previous elastic modeling (point A and D of Figure 2.a). For the type II specimen, all specimens were delaminated at the interface between layers not only at low temperature $\left(6^{\circ} \mathrm{C}\right)$ but also at high temperature $\left(20^{\circ} \mathrm{C}\right)$.
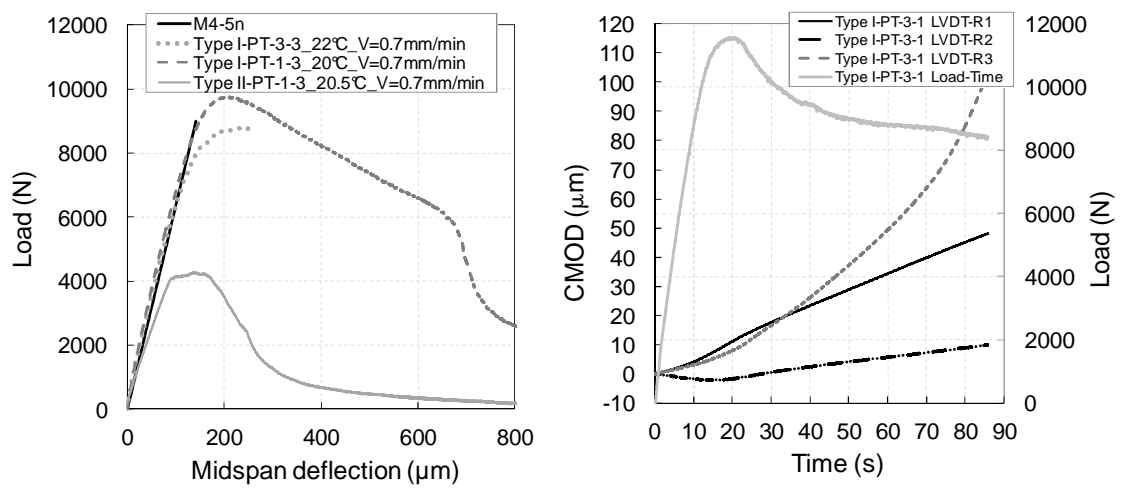

Figure 5. (a) Load-deflection curve of different types of specimen; (b) Crack mouth opening displacement measured by LVDT 
In the modeling, the asphalt modulus value was taken from its master curve at the test temperature and by converting the static test duration $(\mathrm{T})$ into the frequency $(\mathrm{f}=1 / \mathrm{T})$. In Figure 5.a, it is shown that the maximum load of type I specimen is about 50\% more higher than the maximum load of type II specimen. The dissymmetric specimens were successfully delaminated as explained previously in the M4-5n analytical analysis. The combined approach with the 4PB test and M4$5 n$ can evaluate the bonding between layers.

\section{Stress intensity at edge of interface and energy release rate}

According to the experimental results, the delamination is usually dissymmetric. Knowing the failure load (experimentally determined) for a specimen pre-crack length $\mathrm{a}_{0}$, the energy $\mathrm{W}\left(\mathrm{a}_{0}\right)$ stored in the specimen for this load was calculated. It performs the same calculation for a pre-crack length $\mathrm{a}_{0}+\mathrm{da}$, and the energy release rate was calculated by the relation presented in Eqn. (9).
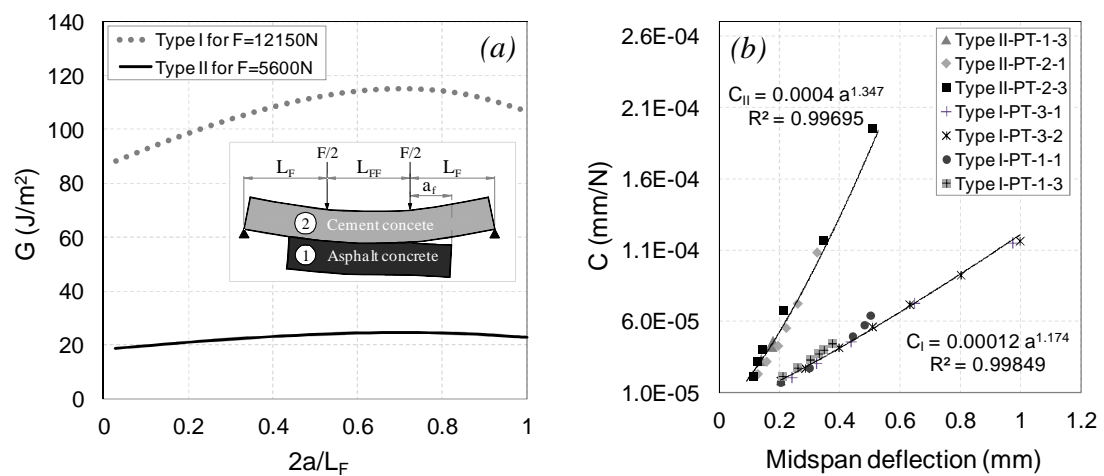

Figure 6. (a) Evolution of $\mathrm{G}$ for different types of specimen; (b) Compliance curves $\mathrm{C}=\mathrm{R} \cdot \mathrm{a}^{\mathrm{n}}$ for different types of specimen $\left(\right.$ at $20^{\circ} \mathrm{C}$ )

The evolution of the energy release rate is given in function of the normalized crack length $2 \mathrm{a} / \mathrm{L}_{\mathrm{F}}$ (Figure 6.a). Based on the derivative of the energy release with respect to the crack length, the crack growth is stable at the crack length of $50 \mathrm{~mm}$. In the other way, the energy release rate can also be determined experimentally by using the compliance method. From the load-deflection curve, the relation of compliance is determined. The compliance $\mathrm{C}$ is, in general, expressed by $\mathrm{C}=\mathrm{u} / \mathrm{P}$ where $\mathrm{u}$ is the midspan deflection related to the load P. Figure 6.b represents the compliance curve for different type of specimens. The compliance versus respective crack length a can be plotted and fit with the expression $C=\operatorname{Ra}^{\mathrm{n}}$. Therefore, the energy release rate can be found as $G=\frac{P^{2}}{2 b} n R a^{n-1}$. Table III shows a summary of the interface stress intensity and the energy release rate which are comparable to the values found in literature [1]. The results show that the interface normal and shear stress of type I specimen are approximately 50\% higher than 
those of type II specimen. But due to the self weight effect of asphalt layer on failure, the type II specimen test needs to be improved.

Table III. Stress intensity at the interface and energy release rate

\begin{tabular}{llllll}
\hline \multirow{2}{*}{ Specimen type } & \multirow{2}{*}{ Failure load (N) } & $\tau$ & $v$ & \multicolumn{2}{l}{$\mathrm{G}\left(\mathrm{J} / \mathrm{m}^{2}\right)$ for a crack length of 2mm } \\
\cline { 5 - 6 } & & $(\mathrm{MPa})$ & $(\mathrm{MPa})$ & Model & Experiment \\
\hline Type I & $9760-12150$ & $0.36-0.41$ & $0.99-1.14$ & $88-98$ & $82-106$ \\
Type II & $4300-5600$ & $0.17-0.21$ & $0.49-0.59$ & $19-28$ & $64-83$ \\
\hline
\end{tabular}

\section{Conclusions}

Experimental results on bilayer specimens, in accordance with quasi-analytical analysis given by the M4-5n, have demonstrated that the proposed 4PB test can determine the interface behavior of bilayer materials, asphalt-concrete and concrete-asphalt. The crack growth was monitoring by means of a LVDT technique. An approximate crack length was obtained. For better measuring the crack length and understanding the failure phenomenon, the Digital Image Correlation technique will be used for the next experimental campaign. For the geometry chosen, the specific test has shown mixed mode failure at the interface between layers. Comparisons with experimental results and analysis of failure modes given above demonstrate that the M4-5n can be used effectively for designing the specimen and as well as for analyzing the test.

\section{References}

[1] Tschegg, E.K, Macht, J., Jamek, M., Steigenberger, J., (2007), ACI Materials Journal, Title no. 104-M52, pp. 474-480.

[2] Chabot, A., (Juin 1997), Analyse des efforts à l'interface entre les couches des matériaux composites à l'aide de Modélisations Multiparticulaires des Matériaux Multicouches (M4), ENPC - PhD thesis.

[3] Caron, J. F., Diaz Diaz, A., Carreira, R. P., Chabot, A., Ehrlacher, A., (2006), Comp. Sc. and Technology, vol. 66, n. 6, pp. 755-765.

[4] Pouteau, B., (Dec. 2004), Durabilité mécanique du collage blanc sur noir dans les chaussées, $\mathrm{PhD}$ thesis, Ecole Centrale de Nantes.

[5] Chabot, A., Pouteau, B., Balay, J.-M., De Larrard, F., (2008). In: Pavement Cracking, Proc. of the 6th Int. RILEM Conf., pp. 13-23, Al-Qadi, Scarpas and Loizos (Eds), CRC Presse.

[6] Achintha, M., Burgoyne, C.J, (2011), Construction and Building Materials, Vol. 25, pp. 2961-2971.

[7] Le Corvec, G. (2008), Simulations des effets du retrait du béton de ciment sur la flexion de matériaux de chaussées fissurées, Master thesis, Univ. Nantes.

[8] Hun, M., Chabot, A., Hammoum, F., (2011). Proc. of the $20^{\text {éme }}$ Congrès Français de Mécanique, paper n. 569, Besançon, France. 